\title{
SÉRIE MAPAS
}

Cartography Series

Serie Mapas

Talles Lopes de Oliveira [Universidade Estadual de Goiás, Brasil]*

LOPES, Talles. Série Mapas. Revista Poiésis, Niterói, v. 23, n. 39, p. 102-114, jan./jun. 2022. [DOI: https:// doi.org/10.22409/ poiesis.v23i39.52951]

Este documento é distribuído nos termos da licença Creative Commons Atribuição-NãoComercial 4.0 Internacional (CC-BY-NC) (C) 2022 Talles Lopes
Assim como em Terra Brasilis (1519), grande parte dos mapas coloniais do Brasil estão marcados por um evidente contraste entre um Leste colonizado e nomeado com topônimos europeus, com um Oeste desconhecido, representado como um grande vazio continental ou uma região idílica cheia de riquezas e criaturas mitológicas. Esse tipo de leitura do território está ligada ao imaginário colonial das primeiras invasões bandeirantes no Brasil central, que compreendiam o Oeste como um espaço exótico e selvagem passível de ser colonizado.

A construção da narrativa colonial sobre o Oeste do Brasil como um lugar a ser explorado foi resgatada pelo estado brasileiro no século XX, tornando-se enredo do processo de modernização e unificação territorial que visava ocupar o interior do país, resultando na construção de cidades modernas como Goiânia e Brasília. Não por acaso, as propagandas da Marcha para o Oeste (1938), programa de expansão agrícola do governo Vargas, e os mapas do Atlas do Brasil (1959) publicado pelo IBGE em função da construção de Brasília, parecem atualizar os contrastes entre Leste e Oeste presente nos mapas coloniais.

Partindo dessas observações, através da produção de um conjunto de mapas venho me dedicando a investigar a contraditória filiação das narrativas do Brasil moderno nas representações cartográficas coloniais, procurando discutir como o aparato técnico-científico e supostamente neutro da cartografia moderna atualizou narrativas mitológicas de dominação do Brasil Central.

*Talles Lopes de Oliveira é artista visual, arquiteto e urbanista graduado pela Universidade Estadual de Goiás. E-mail: talleslopes.go@gmail.com 


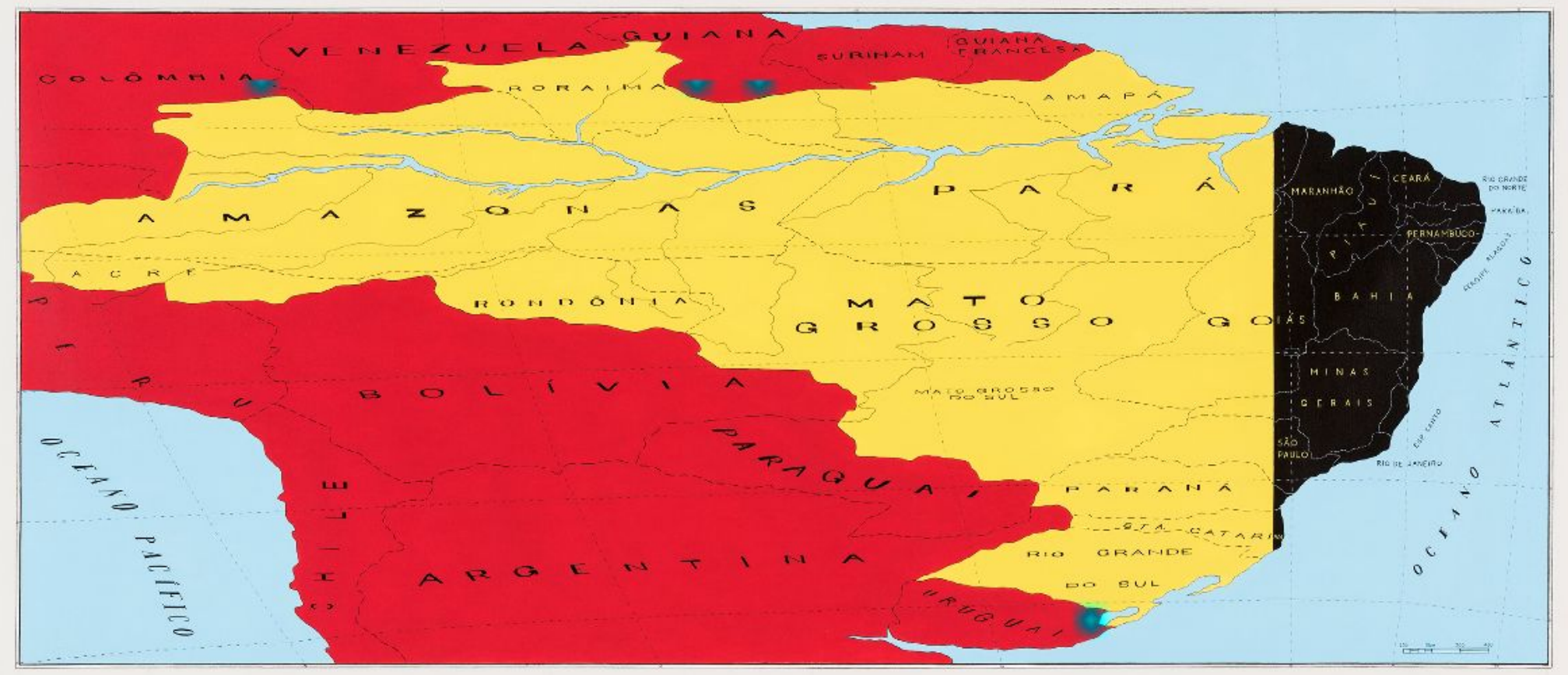

A Marcha. 2018. Acrílica e nanquim sobre tecido. $160 \times 83 \mathrm{~cm}$. 
Condenações. 2016. Tríptico. Acrílica, aquarela e nanquim sobre papel.

$101 \times 72 \mathrm{~cm}$ cada.

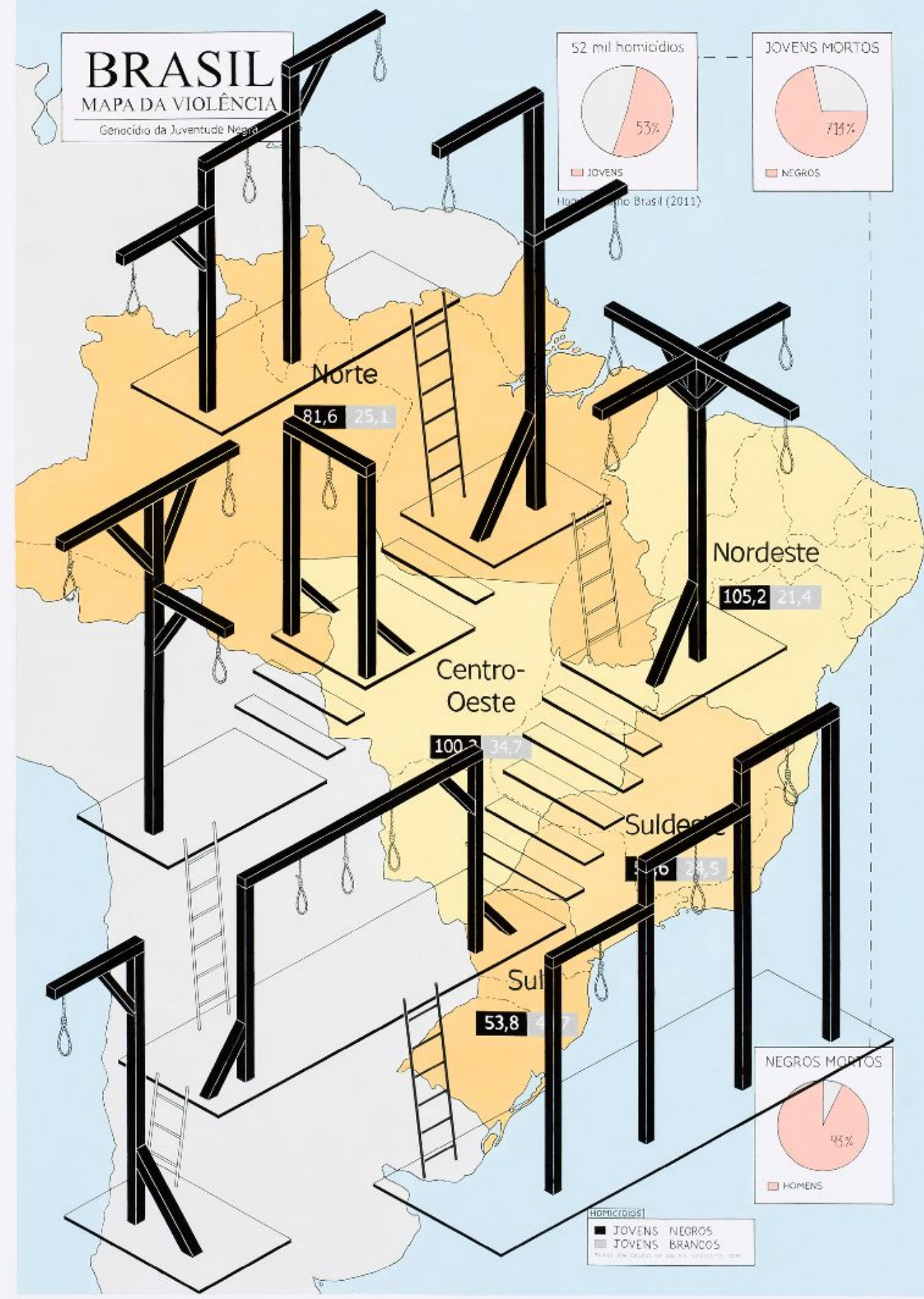




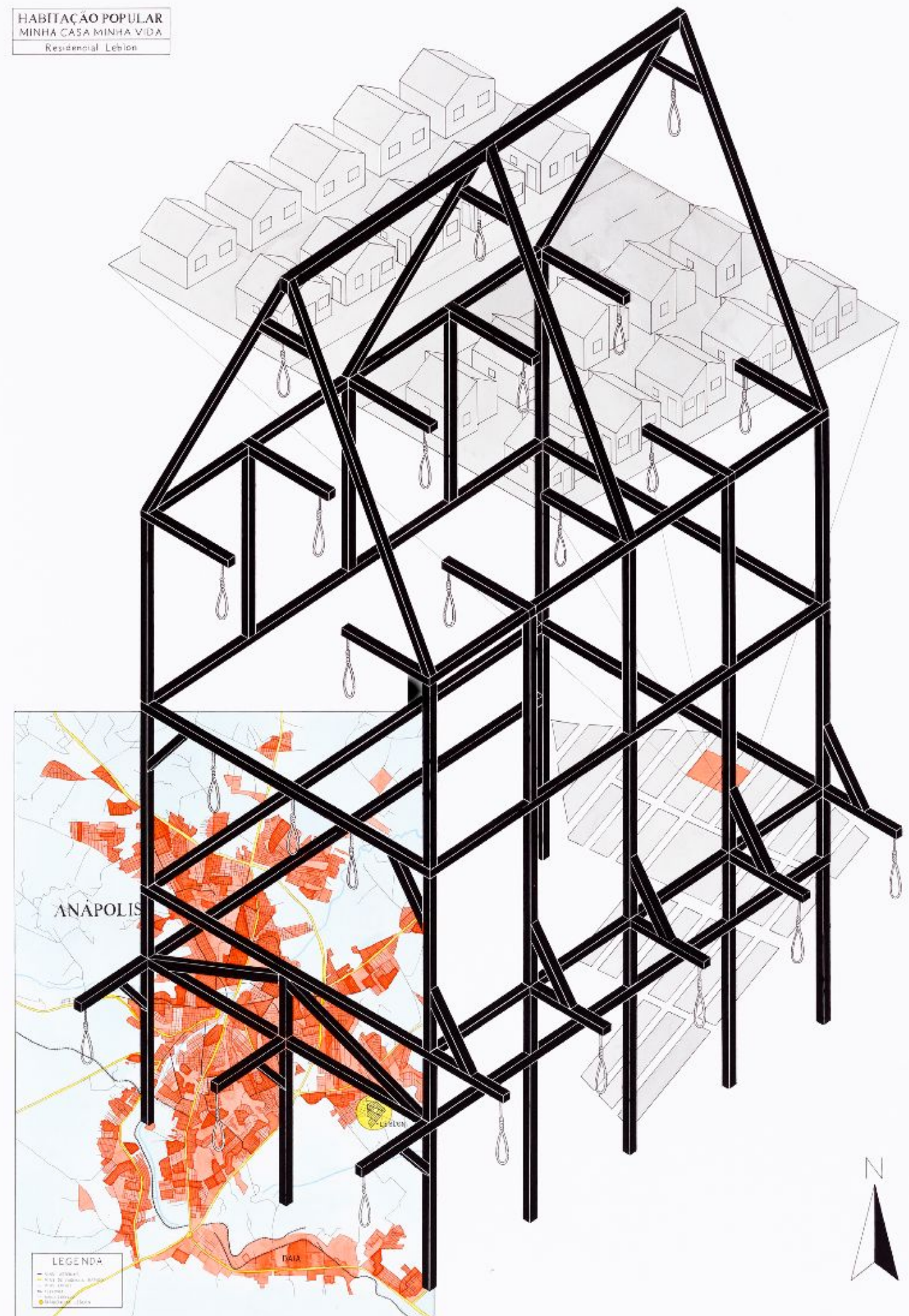

Condenações. 2016. Tríptico. Acrílica, aquarela e nanquim sobre papel.

$101 \times 72 \mathrm{~cm}$ cada. 


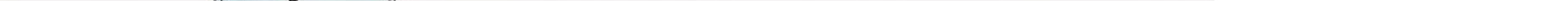

Duo. 2016. Nanquim e aquarela sobre papel. $101 \times 72 \mathrm{~cm}$. 


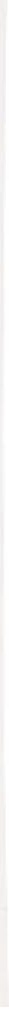

Mapa Estriado. 2020. Acrilica e nanquim sobre tecido. $160 \times 83 \mathrm{~cm}$. 


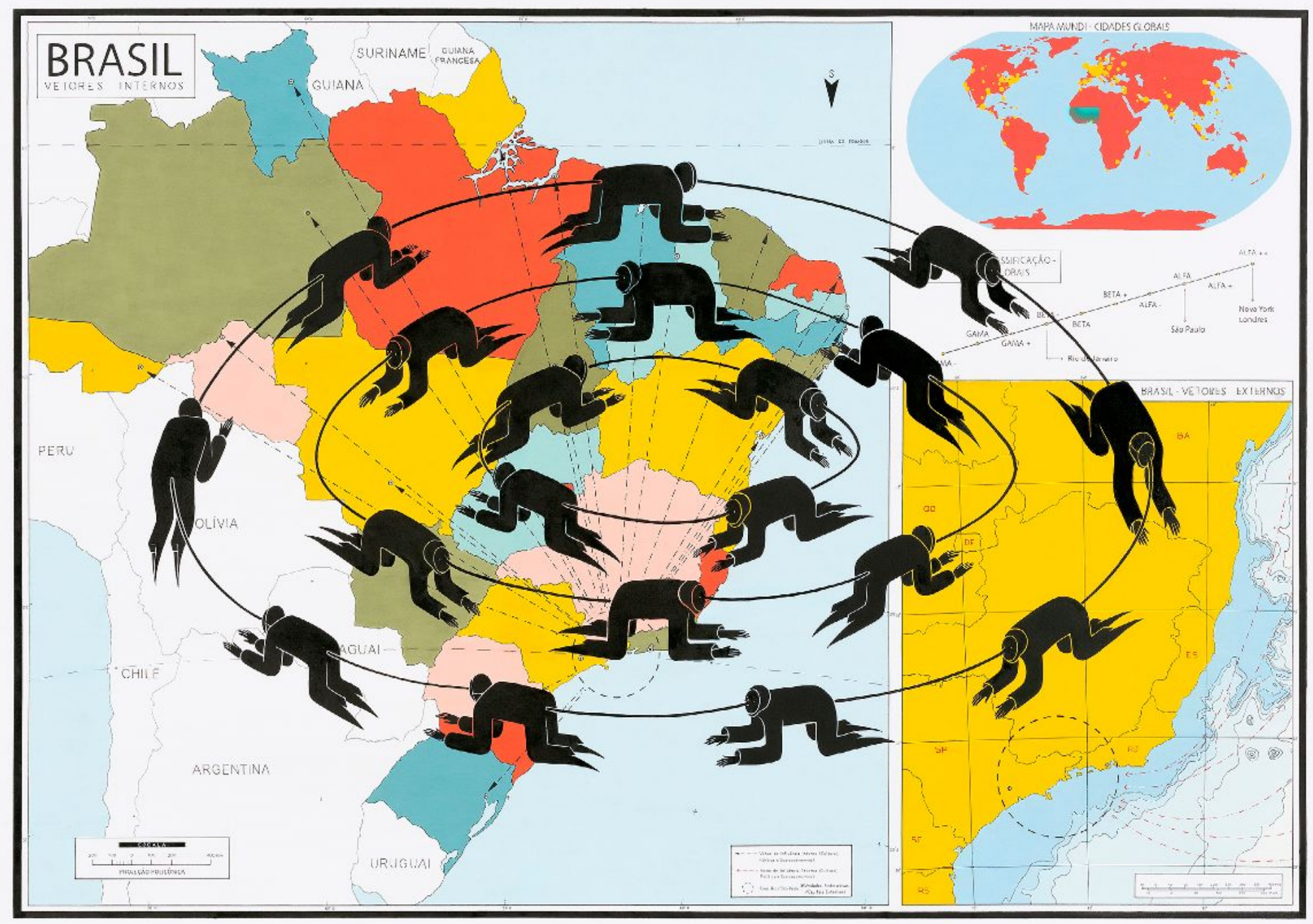

Modelos e circuitos. 2017. Nanquim, guache e acrílica sobre papel. $72 \times 101 \mathrm{~cm}$. 


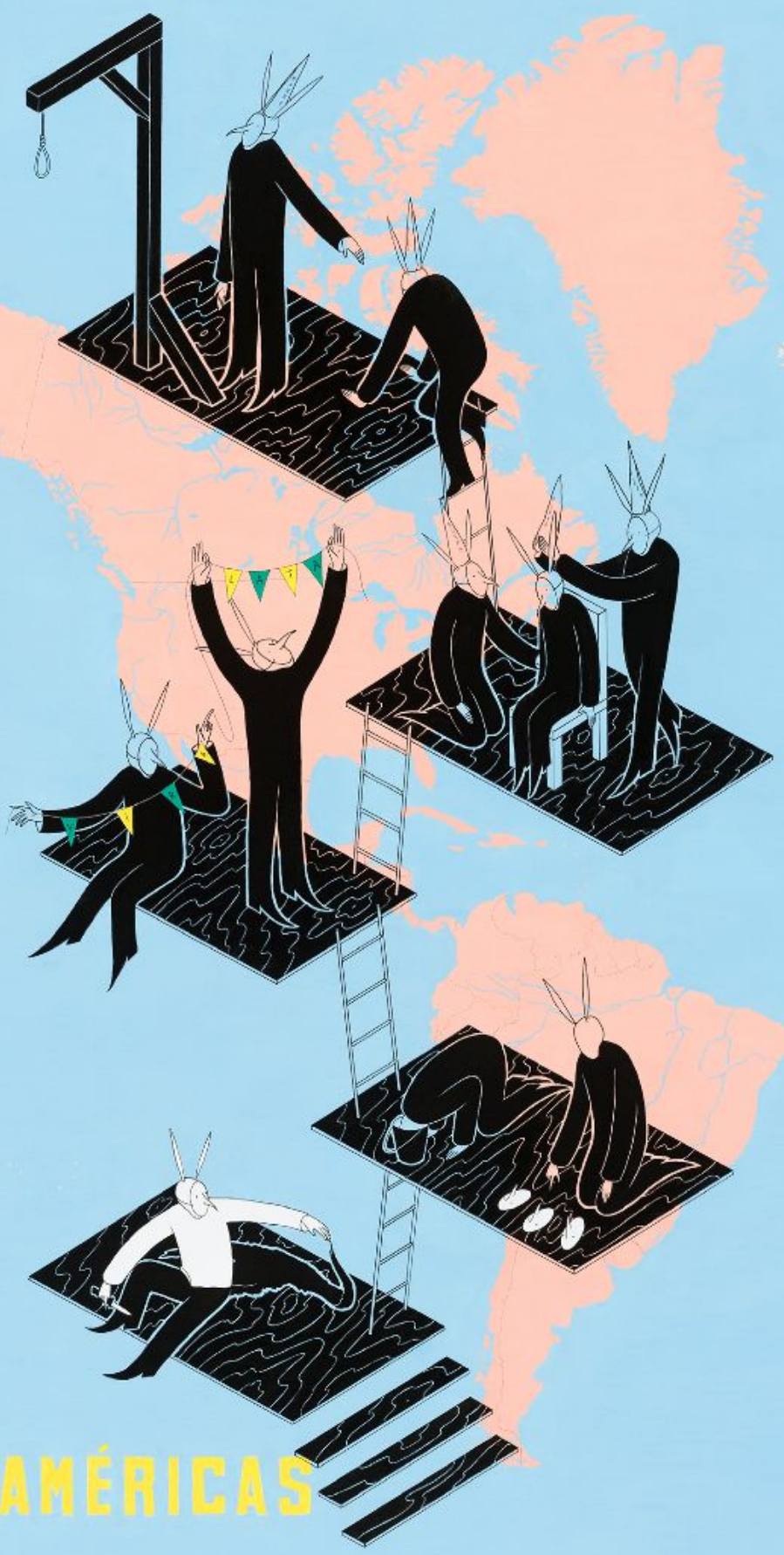

Nelson Rodrigues. 2016. Da série As Américas. Nanquim e acrílica sobre papel. $101 \times 72 \mathrm{~cm}$. 


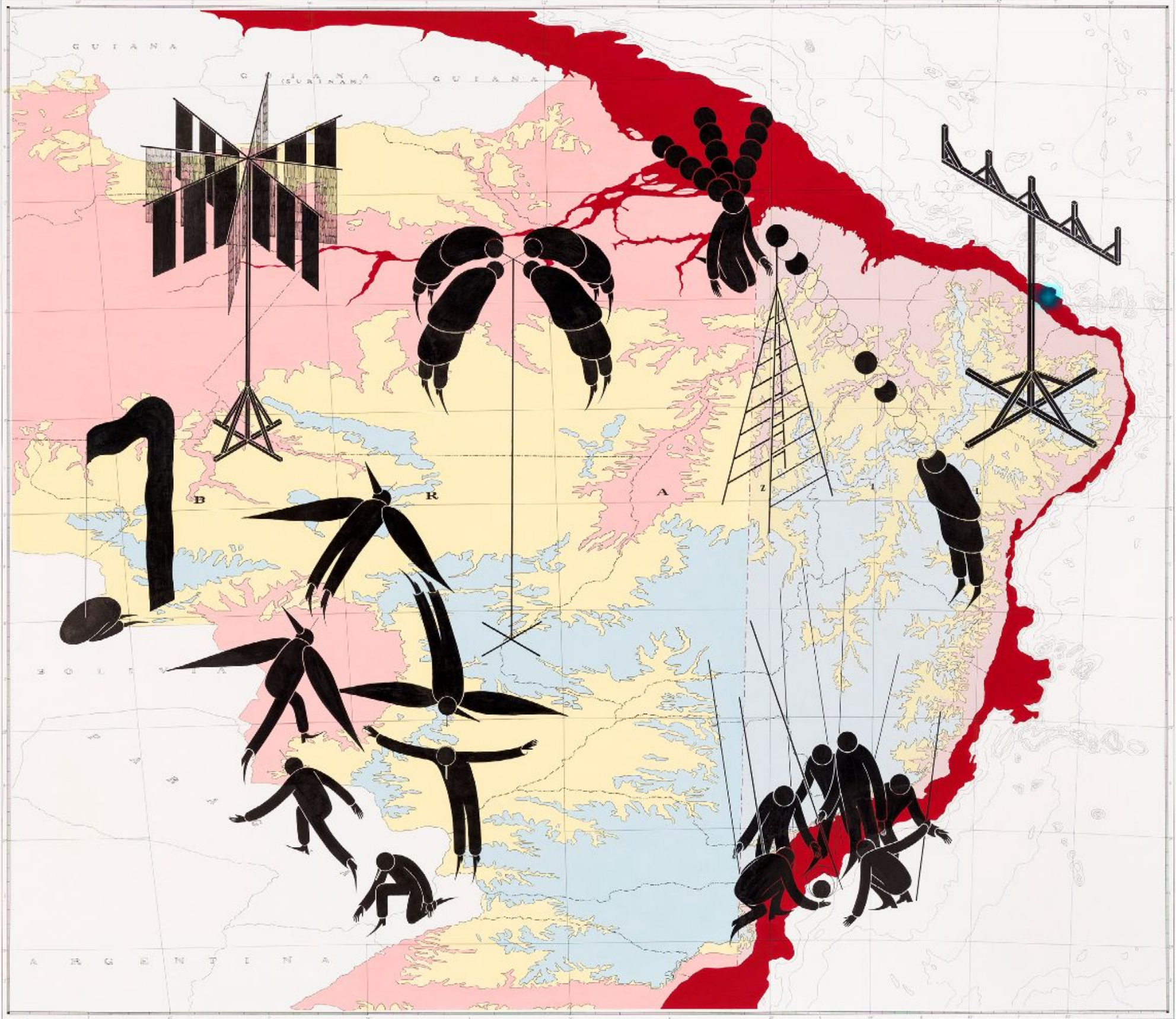

Sem Título. 2018. Guache e nanquim sobre papel. $125 \times 115 \mathrm{~cm}$. 


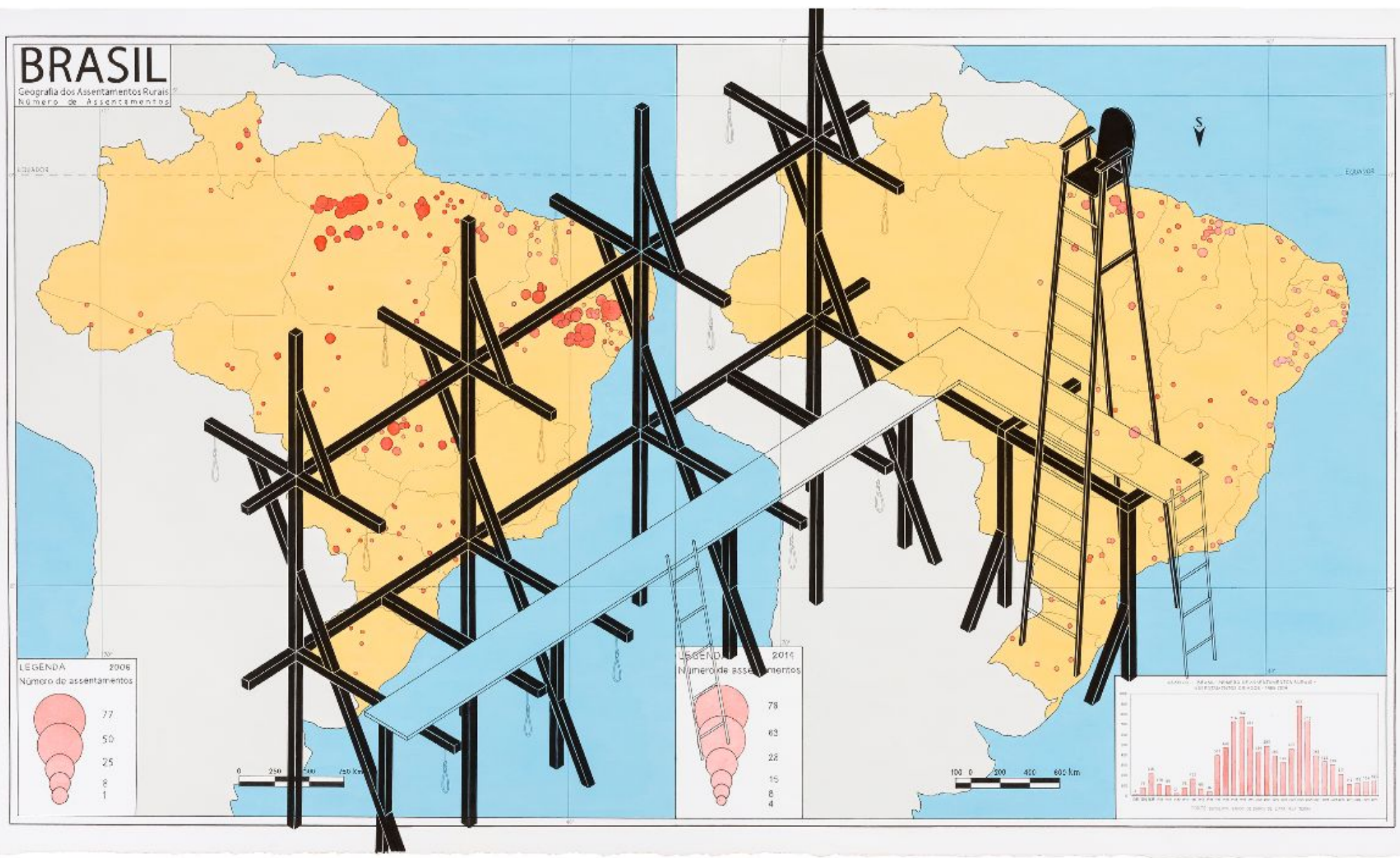

Sem título. 2016. Nanquim e acrílica sobre papel. 59 × 100 cm. 


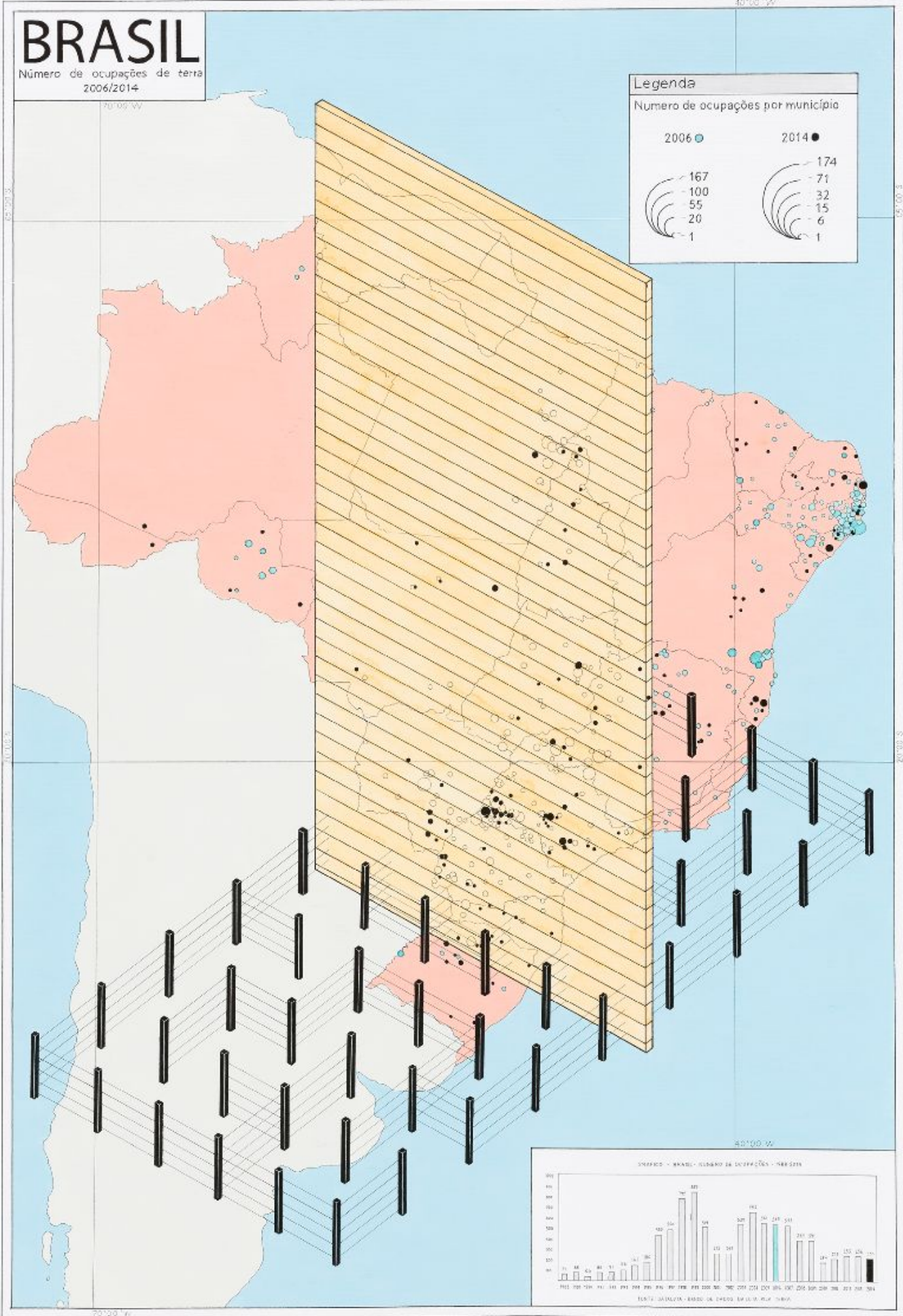

Sem título. 2016. Nanquim e acrílica sobre papel. $72 \times 50 \mathrm{~cm}$. 


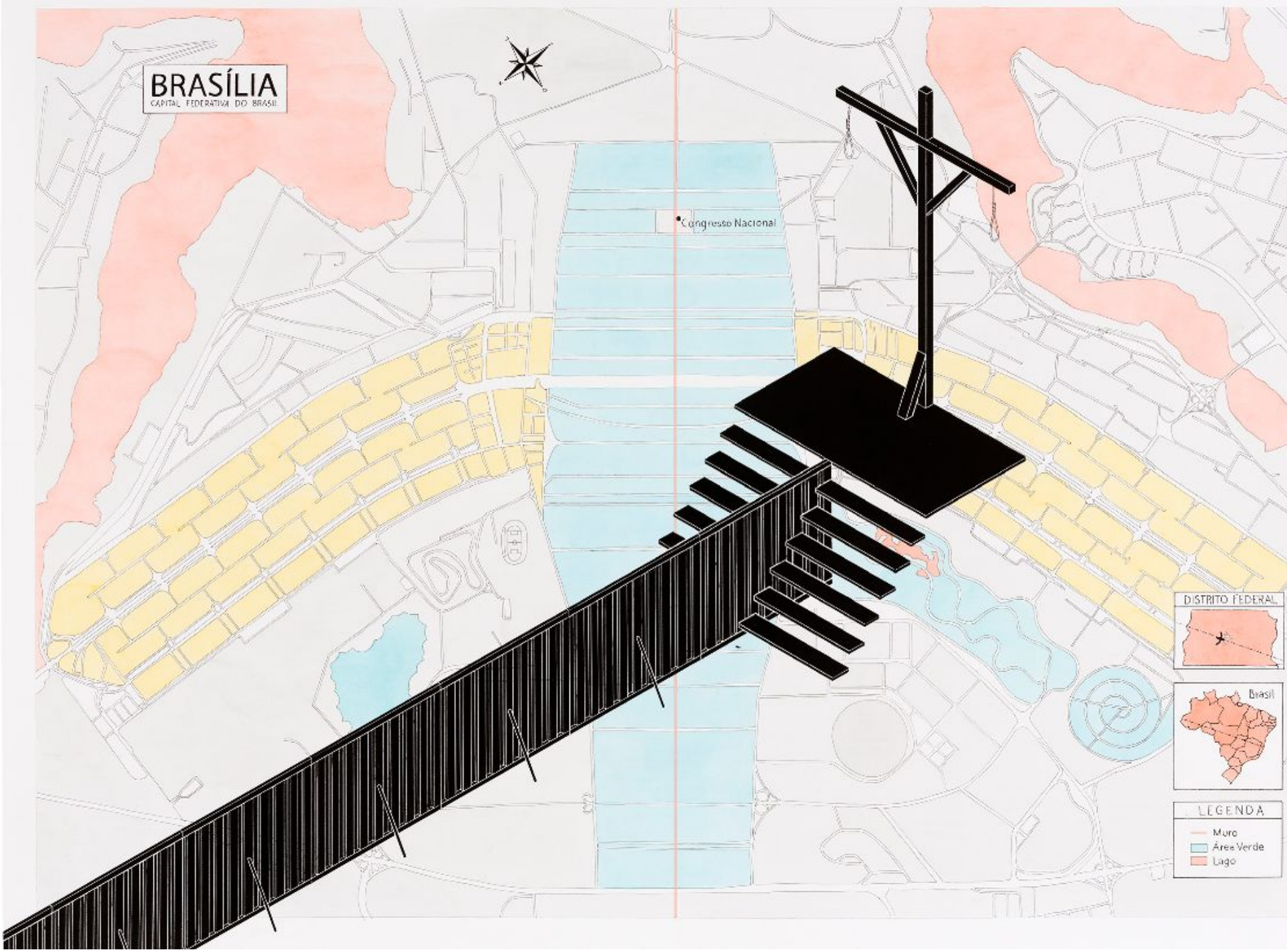

Sem título. 2016. Nanquim e aquarela sobre papel. $72 \times 101 \mathrm{~cm}$. 
Sem título. 2016.

Nanquim e

aquarela

sobre papel.

$87,5 \times 65 \mathrm{~cm}$.

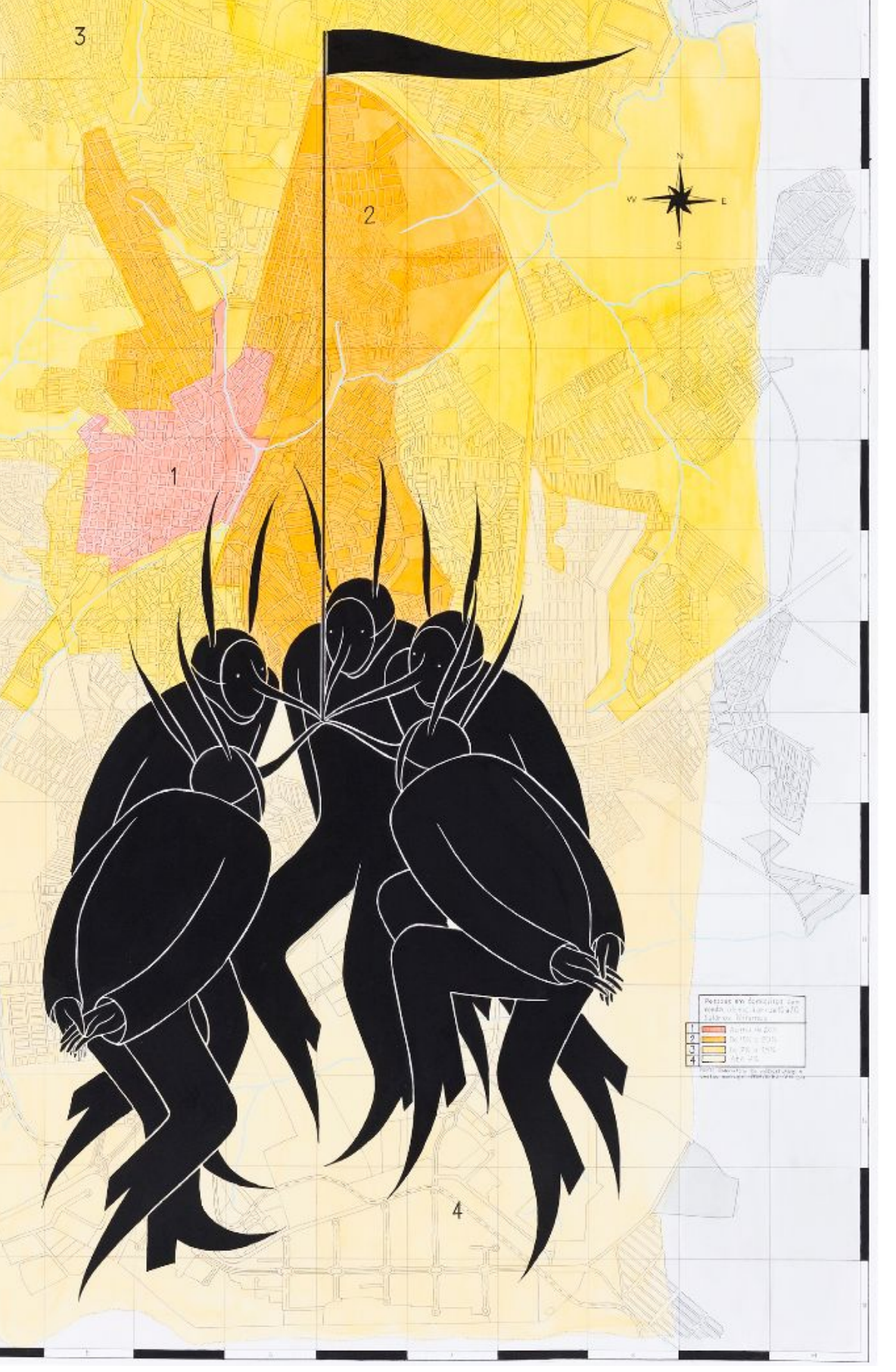

